\title{
Audit Clients Want to Cooperate with their External Financial Auditor, but also Remain at Arm's Length: a Canadian Survey Study
}

\author{
Richard Fontaine ${ }^{1}$ and Luciano Pilotti ${ }^{2}$ \\ ${ }^{1}$ Accounting Department, University of Quebec in Montreal, UQAM, Montreal, Canada \\ ${ }^{2}$ Department of Economics, Business and Statistics, University of Milan, Milan, Italy
}

Correspondence should be addressed to: Richard Fontaine; fontaine.richard@uqam.ca

Received date: 1 May 2015; Accepted date: 22 May 2015; Published date: 19 April 2016

Academic Editor: Zijiang Yang

Copyright (C) 2016. Richard Fontaine and Luciano Pilotti. Distributed under Creative Commons CC-BY 4.0

\begin{abstract}
The objective of our research was to determine what motivates clients to cooperate while at the same time remaining independent with their financial auditors. Both cooperation (working closely) and independence (not being too close) are important in an auditor-client relationship, even though they are opposing characteristics in the Relationship Marketing literature. The problem is that an overly cooperative relationship has been considered a threat to auditor independence; and there is very little research into what would motivate audit clients to be cooperative while respecting the auditor's need to remain independent. To help address this issue, we surveyed 1090 audit clients from Canadian corporations and our results show that audit clients want more of a value-added service from auditors including enhanced communication, resulting in a trusting and cooperative relationship with their financial auditor. Surprisingly the audit clients also want the auditor to remain somewhat distant and independent. Our results contribute to the financial auditing literature as well as to the audit practice
\end{abstract}

Keywords: Auditor-Client, Relationship Marketing, Independence, Cooperation, Commitment, Trust, Communication, Buyer-Seller.

\section{Introduction}

The purpose of this research is to determine what causes clients (buyers) to cooperate with their financial auditors (sellers) and what influences clients to remain at arm's length from their auditors.

In a previous research project, it was determined that the audit client preferred 
more of a close and cooperative relationship approach with their auditor (Fontaine and Pilote, 2011). The client's relationship approach with the auditor was determined using a multi-item measurement model from the Relationship Marketing literature (Kaufmann and Dant, 1992). Surprisingly, Fontaine and Pilote (2011) also found that clients want to remain at arm's length (independent) with their auditors. The reason this finding is surprising is that in the Relationship Marketing literature, the arm's length variable is an opposing variable in comparison with the cooperation variable: a buyer either is cooperative with the seller or at arm's length, but not both (Gronroos, 1991; Lui and Ngo, 2012; Sheth and Parvatiyar, 2000; Viia and Grönroos, 2015).

In this research, we add to the abovementioned study, and we use survey data collected from Canadian corporations to investigate the determinants of the client's preference for both a cooperative and an arm's length relationship.

Client cooperation is important since the auditor needs the client to provide corporate information necessary for the auditor to conduct the audit service (Herda and Lavelle, 2012; Rennie et al. 2010). Clients are privy to more specific information about their corporations than are the auditors (referred to as information asymmetry in favor of the client); and this information asymmetry has been considered an important problem to solve in auditor-client relationships (Ruyter and Wetzels, 1999).

However, in addition to client cooperation, the relationship between the auditor and the client needs to be conducted at arm's length, due to the necessity of auditor independence (IESBA, 2013; IFAC, 2006). To the best of our knowledge, no buyer-seller relationship requires both cooperation and the maintenance of an arm's length distance. Therefore, based on the theoretical and empirical models of Morgan and Hunt (1994) and Kaufmann and Dant (1992), this study attempts to determine the factors that influence the client's preference to cooperate while remaining at arm's length.

This study is different from other buyerseller relationships presented in the Marketing literature. The main component that differentiates our study from other buyer-seller relationships is the presence of a third party user as a key influencer of the client-auditor relationship (which we will be discussing in the following section). Moreover, very few empirical studies that use Marketing to examine auditor-client relationships are available in the literature (Ruyter and Wetzels, 1999), even though the use of Marketing could help better understand this relationship (Beattie, 2001). Our paper is organized as follows. We present a brief literature review followed by our hypotheses, justified by theoretical and empirical research. We then present the results, a discussion, the limitations, and future research opportunities.

\section{Literature Review}

The auditor-client relationship is different from most of the buyer-seller relationships documented in the marketing literature, primarily due to the requirement of the auditors to remain at arm's length from their client (Beattie, et al. 2001; CICA, 2012; Kleinman et al. 2000). In addition to an arm's length relationship, the auditor-client relationship needs to be cooperative, since the auditor and client need to interact, and the auditor relies on client provided information.

The reason the auditor needs to remain at arm's length from the client is the presence of third-party users. Even though the client pays the auditor for the audit service, it is the third-party user who actually is the intended client (such as the banker, the investor, or other interested parties) (CICA, 2012). There are other two-party relationships that include a third-party, such as doctors and patients (where the patient is the user of the service, paid for by the government or an insurance company). However, to the best of 
our knowledge, there is no documented buyer-seller relationship, where the buyer of the service is not the intended user of the same service. The fact that the intended user of the audit service is a third-party user is the reason for which the auditor and the client need to be at arm's length.

The arm's length variable is important because in the auditor's code of ethics, the auditor is required to remain at arm's length from the client to avoid familiarity threat (IESBA, 2013; IFAC, 2006). Familiarity threat occurs when the auditor has difficulty in conducting the audit using professional skepticism (Arens, 2007).

Professional skepticism, according to audit regulators (CICA, 2012), requires the auditor to not be blind to evidence that could be altered or incorrect (Arens, 2007). This requires the auditor to always have a questioning mind. Therefore, the auditor is not to be overly trusting of the information provided by the client (Rennie et al. 2010). This could put potential strain on the working relationship between the auditor and the client.

The problem is that while assuring professional skepticism and conducting the audit with a critical eye, the auditor needs a trusting, collaborative working relationship, because the auditor needs the help of clients that possess specific corporate information (Rennie et al. 2010; Trotman and Cheng, 2012). Without the cooperative help of clients, the transaction cost of the audit could be increased, given the auditor's need to spend increased effort to obtain client information.

The clients' willingness to cooperate with their auditors could be dependent on their perception of the value of the auditor service. In their Relationship Marketing model, Pels et al. (2000) propose that the client's preference for a cooperative and relational approach with their seller is dependent on the client's perception of the seller's service offering. If the client perceives the service as generic and routine, there will be less cooperation. However, if clients perceive the seller's service as unique and value-added, there will be a cooperative relational preference. Therefore, to be able to hypothesize the client's willingness to cooperate with their auditor, it would be important to better understand how the client perceives the audit service.

Based on the Goldman and Barlev (1974) Power model, even though the auditor will provide some unique advice, the majority of the audit service is considered routine with little value added service. As a result, the auditor operates in a buyer's market, where the client can easily replace their service provider (auditor), which is the main source of power for the client (Goldman and Barlev, 1974).

In contrast to Goldman and Barlev (1974) Power model, Beattie et al.( 2000) present the concept of an added-value audit in which the findings of an audit are communicated to the client, which adds value to the client's corporation. Because of this added value, the client could be willing to cooperate during the audit process. The client would not perceive this added-value audit as routine; therefore, some of the unbalanced power would be shifted into the hands of the auditor.

An added-value audit has been shown to reduce the risk for clients and increase their strategic advantages in the marketplace (Eilifsen et al. 2001). This is even more evident when the client offers a diverse and complex portfolio of products and/or services, and when the auditor does not have a good understanding of the client's complex and diverse business offerings.

Therefore, even though the traditional audit service is mostly a routine service with infrequent situations of complexity (Goldman and Barlev, 1974), during and after the audit service, the auditor can provide invaluable business advice, which could help the client (Beattie et al. 2000; Eilifsen et al. 2001). This 
additional information is considered the added-value audit. By providing a valueadded audit, auditors are able to shift the asymmetry of power from the client to themselves, balancing the relationship. In extreme cases, the balance of power could shift from auditor to client; however, generally there should be a balance of power between the auditor and the client.

This balanced power, where the auditor needs client information to conduct the audit, and where the client wants valuable information from the auditor (information that could help their business), should increase the level of auditor-client cooperation. Both parties should be motivated to increase their level of cooperation towards each other to assure access to one another's information. Based on Game Theory, the concept of "addedvalue" has been used to determine the amount of power that one party brings to the table in a card game (Brandenburgern and Nalebuff, 1996). These authors claim that you cannot get more from a relationship than the added-value that you bring to the table. Moreover, researchers in Relationship Marketing claim that interdependent, cooperative relationships lower transaction costs and improve the quality of the service delivered at a lower cost (Heide \& John, 1992; Sheth and Parvatiyar, 2000; Williamson, 1985).

Even though audit theory has shown that the client possesses power because the audit service is routine (Goldman and Barlev, 1974), other research has looked beyond the traditional audit. The new value-added audit that provides valuable information to the auditor balances the power asymmetry and promotes a more collaborative relationship. We base our auditor-client model on the value-added audit, promoting client cooperation. However, we also maintain that the client should respect the auditor's code of ethics and encourage the auditor to conduct the audit while remaining at arm's length. As previously mentioned, this is what differentiates our buyer-seller model from other models documented in the marketing literature.

Relationships between buyers and sellers in the marketing literature are typically positioned as either relational (RA) or transactional (TA) (Gronroos 2000). Relationships that are TA are typically conducted at arm's length and independent and are categorized as Transactional relationships (Lui and Ngo, 2012; Sheth and Parvatiyar, 2000; Viio and Grönroos, 2015). These transactional relationships are also defined as competitive and conflicting. The opposing relationship axiom is one defined as cooperative and interdependent (Gronroos, 2000; Sheth and Parvatiyar; Viio and Grönroos, 2015). To the best of our knowledge, a relationship that requires cooperation and needs to remain at arm's length has not yet been modeled in the Relational Marketing literature. Therefore, it would be important to contribute to the Marketing literature a model that determines the factors that influence cooperation between a buyer and a seller, while respecting the need to maintain distant and remain at arm's length.

\section{Hypotheses (Theoretical Framework)}

The following are the individual items (variables) that make up our hypotheses (see Figure 1). 


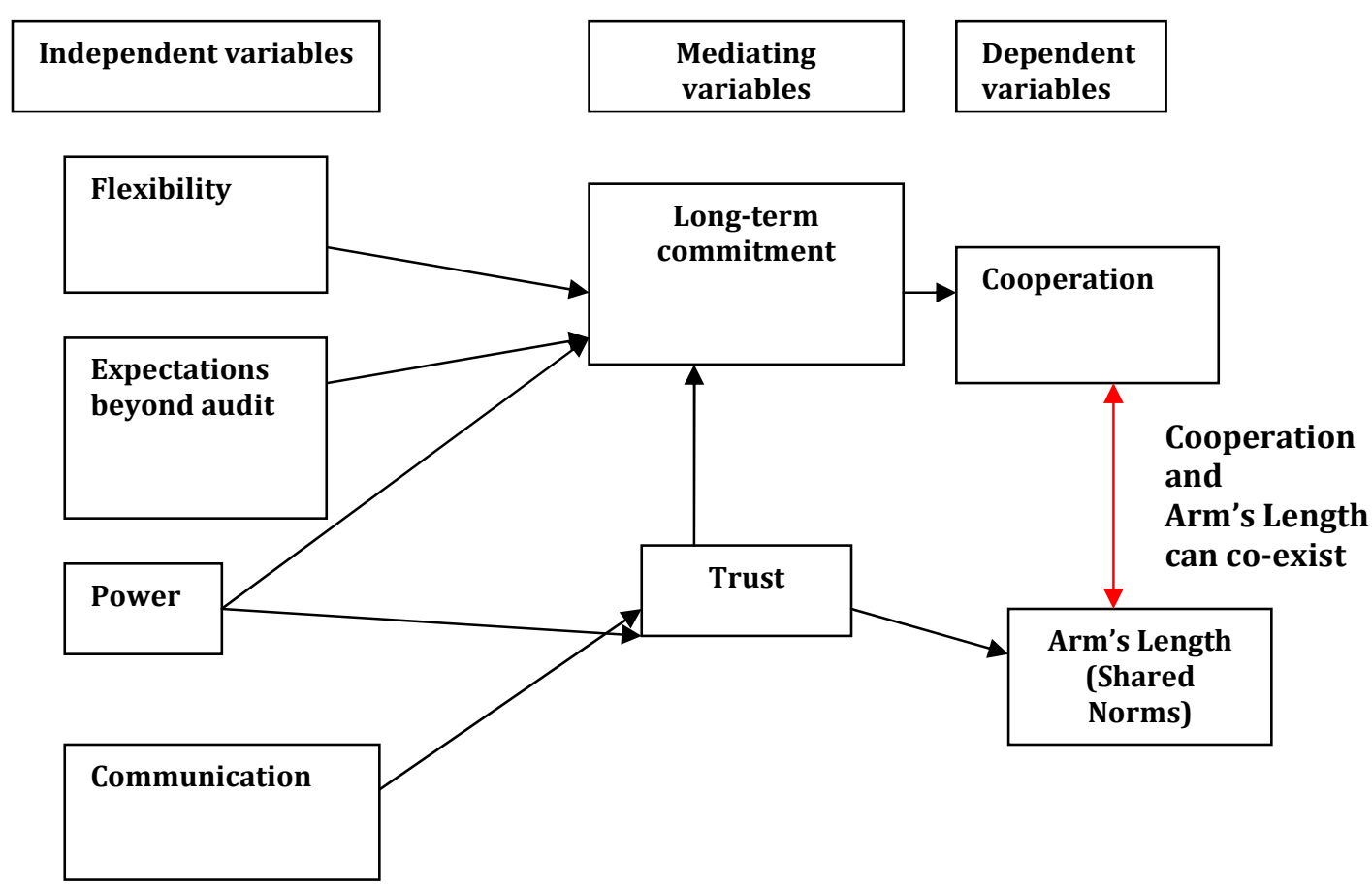

Figure 1: Determinants of clients' preference to cooperate

\section{Power, Commitment, and Trust}

The use of Power by one of the parties in a relationship is shown to impair relationship success; whereas, restraining power has been shown to enhance relationship success (Dwyer et al.1987; Morgan and Hunt, 1994).

In the audit-client relationship, understanding the use or restraint of power is important since it is theorized that the client possesses more power than the auditor, justified by Resource Dependency theory (Goldman and Barlev, 1974). This is especially important when the corporate structure of clients is complex and when the client portfolio is vast and differentiated. In this case, the client would want to have access to valuable auditor information, reducing the client's transaction cost of obtaining value-added information (which auditors possess once they conduct the audit). Therefore, the client should be willing to restrain their power in order to receive value-added information, which will in turn redistribute power back into the hands of the auditor. 
Table 1: Variable inter-correlations

\begin{tabular}{|c|c|c|c|c|}
\hline Variable & $\begin{array}{l}\text { Cooperation } \\
\text { Solpref } 6\end{array}$ & $\begin{array}{l}\text { Arm's Length }{ }^{\circledR} \\
\text { Solpref } 3\end{array}$ & $\begin{array}{l}\text { Trust } \\
\text { Solpref2 }\end{array}$ & $\begin{array}{l}\text { Commitment } \\
\text { Solpref4 }\end{array}$ \\
\hline Power Restraint (Powpref1 and 2) & . & & $\begin{array}{l}. .267^{* *} \\
.203^{* *}\end{array}$ & $\begin{array}{l}.164^{* *} \\
.181^{* *} .\end{array}$ \\
\hline Trust (Solpref2) & $.327^{* *}$ & $-.139 *$ & & $.257^{* *}$ \\
\hline Flexibility (Flepref 1) & & & . & $.326^{* *}$ \\
\hline Communication (solpref1) & & & $.332^{* *}$ & . \\
\hline Commitment (Solpref4) & $.239 * *$ & .008 & $.257^{* *}$ & $.210^{* *}$ \\
\hline Expectations beyond audit (Rolpref1) & & & .. & $.255^{* *}$ \\
\hline Arm's Length ® (Solpref3) & $-.139 *$ & & $-.306^{* *}$ & -.008 \\
\hline
\end{tabular}

**. Correlation is significant at the 0.01 level (1-tailed).

*. Correlation is significant at the 0.05 level (1-tailed)®. The Solpref3 variable is a reverse item;

therefore a negative correlation actually represents a positive relationship and a positive

correlation actually represents a negative relationship.

In Morgan and Hunt's (1994) CommitmentTrust model, it was argued that the use of Power was exercised in 'sick' relationships and that restrained power leads to long-term commitment and trust. Similarly, it was proposed that in relationships between retailers and vendors, when there was the presence of power and influence (asymmetrical dependence) by one party, the relationship was less stable and more likely to break up over time (Ganesan, 1994). In addition, when the relationship between auditors and their clients in the Netherlands was studied, it was shown that there was a positive relationship between interdependence (the sharing of power) and relationship commitment (Ruyter and Wetzels, 1999).

Therefore, in line with the reasoning presented above, we hypothesise that the more audit clients restrain their use of power, the more they will be willing to be trustworthy and commit to a long-term relationship, to reduce the risks and cost of Non-Information.
H1: There is a positive relationship between power restraint and commitment.

H2: There is a positive relationship between power restraint and trust.

\section{Flexibility and Commitment}

When circumstances change, while two parties are interacting, the demonstration of flexibility has been shown to help strengthen the relationship (Kaufmann and Dant, 1992). Gronroos (2000) argues that flexibility shown by the supplier of a service adds to the service quality perceived by the customer. Flexibility has been shown to increase commitment. For example, the Ritz Carleton has a flexible database system that maintains personal client data, allowing the Ritz to provide personalized services to the client such as favorite newspapers and meals without asking (Sheth and Parvatiyar, 2000). In the auditor-client relationship, both agents (the auditor and the client) should be motivated to demonstrate flexibility to reduce power asymmetry: the client demands a more personalized service and 
the auditor requests more information about the client's organizational context. Therefore, we hypothesize that client flexibility will lead to client commitment.

H3: There is a positive relationship between flexibility and commitment.

\section{Expectations beyond audit and Commitment}

The added-value audit is presented by Beattie et al. (2000) who argue that clients rely on advice from their auditors that extends the audit service. The auditor provides this additional advice without extra fees. When a supplier offers advice that goes beyond the paid audit service, commitment towards a long-term relationship is enhanced (Gronroos, 1997). The company specific information in the hands of the client will be shared with the auditor willingly, rebalancing the power asymmetry and reducing the distance between the knowledge (information) needed by the auditor to conduct the audit and the knowledge (information) controlled by the client. Therefore, we hypothesize that a preference for service that extends beyond the audit service will lead to a preference for a more committed relationship.

H4: There is a positive relationship between Expectations and Commitment.

\section{Communication and Trust}

Open communication is shown to increase levels of Trust in buyer-seller marketing models (Morgan and Hunt, 1994) including the audit-client relationship (Rupter and Wetzels, 1999; Rennie et al. 2010) in particular, because trust should reduce the efforts to obtain information in the case of unbalanced asymmetry. In a study of auditors and clients during situations of disagreement, it was found that open communication was positively associated with trust (Rennie et al. 2010).
Therefore, we hypothesize that the client's preference for increased communication will lead to a higher level of trust.

H5: There is a positive relationship between Communication and Trust.

\section{Trust, Commitment, and Cooperation}

Trust was theorized and empirically tested as a key antecedent to relationship commitment in two published studies that serve as the basis for our conceptual framework (Morgan and Hunt, 1994; Ruypter and Wetzels, 1999). Trust in another party is defined as the expectation that the party will behave according to expectations and as a willingness to rely on another party (Gronrros, 2000).

In addition, Trust and Commitment are key mediating variables in the CommitmentTrust model (Morgan and Hunt, 1994). These two variables (Commitment and Trust) showed significant influence on a party's willingness to cooperate. In fact, it has been argued that Commitment is present in every successful relationship between business parties (Gronrros, 2000). Empirical evidence from Axelrod's (1984) repeated games shows that cooperation between parties rises with the presence of long-term commitment (Rokkan et al. 2003). This is because in repeated games defectors (non-cooperators) are punished in future games.

The desire for more information should result in the client cooperating in order to obtain added-value information. In turn, the auditor requires information from the client to perform the audit. Our model is a form of a cooperative convergent model where in the case of high asymmetry there will be cooperative behaviour by both the auditor and the client in order to reduce the cost of Non-Knowledge. The cost of Non-Knowledge for the auditor is further audit costs to obtain additional information in the absence of client cooperation. On the other hand, the cost of Non-Knowledge for the client is not receiving an added-value audit in exchange

Richard Fontaine and Luciano Pilotti (2016), Journal of Accounting and Auditing: Research \& Practice, DOI: $10.5171 / 2016.207562$ 
for the audit fees paid (the client will receive the standard audit service).

Therefore, we set the Commitment and Trust variables as key mediating variables (see Figure 1). We then hypothesize that higher Trust will lead to higher Commitment, and higher Trust and Commitment will lead to higher Cooperation.

H6: There is a positive relationship between Trust and Commitment.

H7: There is a positive relationship between Commitment and Cooperation.

H8: There is a positive relationship between Trust and Cooperation.

\section{Arm's Length (Shared norms), Commitment, and Trust}

When two parties share common norms there is a greater chance for relationship success, particularly because there will be reduced uncertainty for both parties (Rokkan et al. 2003).

In the auditor-client relationship, an important norm that auditors must follow is to remain at arm's length from the client as discussed above. In addition, the auditor sends an independence letter to the client to assure the client adheres to this auditor obligation (CICA, 2006). It is not the obligation of the client to remain at arm's length from the auditor (but rather the auditor's obligation); however, if the client does adhere to this important auditor norm, it would result in the sharing of a norm. It has been shown that shared norms, trust and commitment are interrelated (Morgan and Hunt, 1994; Rokkan et al., 2003 Ruypter and Wetzels, 1999;). Therefore, we hypothesize that when a client prefers commitment and trust, they will also prefer to remain at arm's length, therefore:

H9: There is a positive relationship between Arm's Length (Shared Norms) and Trust.
H10: There is a positive relationship between Arm's Length (Shared Norms) and Commitment.

\section{Method}

We surveyed 1090 Financial Directors from Canadian private corporations with over 100 employees. The participant of the study was randomly chosen as an audit client responsible for the management of the auditor relationship at the client company.

We received 306 completed questionnaires, which allowed us to measure relational preference variables. In our model, we measure four independent variables: Flexibility, Expectations beyond audit, Power, and Communication. In addition, we measure two mediating variables: Long-term commitment and Trust, with the dependent variables set as Cooperation and Arm's Length (see Figure 1).

The analysis to determine relationships among the individual variables is a simple correlation analysis. As neither correlation nor regression analysis provides evidence of causation, it is recommended to rely on a theoretical foundation for guidance on the cause and effect of correlated variables (Gujarati, 2003). Therefore, we rely on the well-cited Commitment-Trust model developed and empirically tested by Morgan and Hunt (1994) to guide the direction of our correlated variables.

The measure we used in our survey to test the audit client's relationship preference was based on a multi-dimensional measurement instrument developed by Kaufmann and Dant (1992). These authors based their measurement model on the theoretical framework of Macneil (1980). The measurement instrument was subsequently operationalized by Fergueson et al. (2005), Fink et al. (2007), Paulin et al. (1997; 2000), and Rokkan et al. (2003) in various industries. Since our measurement model of Kaufmann and Dant (1992) has a sound theoretical foundation (Macneil's 1980 
Relational Exchange Theory), we confirm that measurement items show strong nomological validity.

The relational score of each dimension was determined by finding the mean of the item sums. A Visual Analogue Scale (VAS) of 10 centimetres was used to measure each survey question instead of a Likert Scale in order to achieve maximum variance. The respondent was asked to place an $\mathrm{X}$ on the part of the continuum that best represented their answer, and the respondents answer was reported in centimetres. All the answers in each questionnaire were rated by individuals (raters) that were given clear instructions on how to measure each response accurately and consistently. Our survey scale was tested for unidimensionality using factor analysis, reliability using the Cronback Alpha and Construct Validity was assessed using theoretical justifications.

\section{Results}

The description of our participants is as follows. Male respondents accounted for $69.40 \%$, while $30.60 \%$ of the respondents were female. The average number of years in the current position was 11.50 years, ranging from 0.25 years to a maximum of 55 years. Big- 4 audit firms accounted for $43.90 \%$ and $56.10 \%$ of respondents dealt with Non-Big 4 firms. We did not notice any significant difference in results when we took into account the different demographic information.

The results of the correlations of the independent, mediating and dependent variables are presented in Table 1 . We hypothesized in $\mathrm{H} 1$ that there would be a positive relationship between Power Restraint (Powpref) and Long-Term Commitment (Solpref4) and the results show a significant relationship between these two variables, $\mathrm{r}=.164$ and .167 , $\mathrm{p}$ (onetailed), <.05. Therefore, H1 is supported. The following are the results of hypothesis 2hypothesis 10:
H2: We hypothesized that there would be a positive relationship between Power Restraint (Powpref) and Trust (Solpref2) and the results show a significant relationship between the two variables, $r=.267$ and .203 , $\mathrm{p}$ (one-tailed), < .05. Therefore $\mathrm{H} 2$ is supported.

H3: We hypothesized that there would be a positive relationship between Flexibility (Solpref6) and Commitment (Solpref4) and the results show a significant relationship between the two variables, $r=.326$, $p$ (onetailed), <.05. Therefore, H3 is supported.

H4: We hypothesized that there would be a positive relationship between Communication (Solpref1) and Commitment (Solpref4) and the results show a significant relationship between the two variables, $\mathrm{r}=$ .210 , p(one-tailed), <.01. Therefore, $\mathrm{H} 4$ is supported.

H5: We hypothesized that there would be a positive relationship between Communication (Solpref4) and Trust (Solpref2) and the results show a significant relationship between the two variables, $\mathrm{r}=$ ..332, p(one-tailed), < .05. Therefore, H5 is supported.

H6: We hypothesized that there would be a positive relationship between Trust (Solpref2) and Commitment (Solpref4) and the results show a significant relationship between the two variables, $r=.257$, $\mathrm{p}$ (onetailed), <.01. Therefore, H6 is supported.

H7: We hypothesized that there would be a positive relationship between Commitment (Solpref4) and Cooperation (Solpref6) and the results show a significant relationship between the two variables, $r=.239$, $p$ (onetailed), $<.05$. Therefore, $\mathrm{H} 7$ is supported.

H8: We hypothesized that there would be a positive relationship between Trust (Solpref2) and Cooperation (Solpref6) and the results show a significant relationship between the two variables, $r=.327, \mathrm{p}$ (onetailed), <.01. Therefore, H8 is supported. 
H9: We hypothesized that there would be a positive relationship between Arm's Length (Solpref3) and Trust (Solpref2) and the results show a significant relationship between the two variables, $r=-.306$, $p$ (onetailed), <.05. Therefore, H9 is supported.

H10: We hypothesized in $\mathrm{H} 10$ that there would be a positive relationship between Arm's Length (Solpref3) and Commitment (Solpref4) and the results show a significant relationship between the two variables, $r=$.008, p(one-tailed), <.05. Therefore, H10 is not supported.

Nine of the 10 hypotheses were supported. The only hypothesis that was not supported was H10, which predicted that Commitment would be related to an Arm's Length relationship between the auditor and the client. These results show that when there is Flexibility, Expectations beyond the audit, Power restraint, and Communication (the independent variables) between the auditor and the client, there is an increase in Commitment and Trust (the mediating variables). Furthermore, with the presence of both Commitment and Trust there is more Cooperation between the auditor and the client. However, only when Trust is present is there an Arm's Length relationship between the auditor and the client; Commitment is not related to an Arm's Length relationship (see Figure 1).

\section{Discussion and Management Implications}

In this study, we added to the research of Fontaine and Pilote (2011). These authors found that clients prefer a more cooperative, relational approach with their auditors, measured by using a multi-item summated scale. In this present study we went a step further and analysed the individual items that made up this multi-item scale. These individual items such as flexibility, power, expectations, communication, commitment, and trust, were tested to determine their influence on the client's preference to cooperate and remain at arm's length (mediated by commitment and trust).
The results of our study show that, similar to Morgan and Hunt (1994), power erodes relationship success. When clients restrain their Power they are more willing to be committed and trustworthy (See Hypotheses 1 and 2). These results are contrary to the model proposed by Goldman and Barlev (1974), where it is proposed that even though the auditor does provide helpful advice to the client on occasion, normally the audit service provided is routine. Because of this routine service, the auditor is in a buyer's market and can be easily replaced by the client. As a result, power is asymmetric in the hands of the client.

In contrast to the Goldman and Barlev (1974) model, we propose that even though the audit service is routine and non value added, the client would desire from the auditor helpful advice, referred to as the new valueadded audit (Beattie et al. 2000; Eilifsen et al. 2000). It is proposed in the Relationship Marketing literature that added-value information by a service supplier is a byproduct of a service and an important part of a relational approach (Gronroos, 1991; Ravald and Gronroos, 1996).

Further evidence from our results indicates the client's preference for an added-value service from their auditor. The client's expectation beyond the audit is related to the client's willingness to commit to the relationship (see Hypothesis 4). In addition, the client's preference for more open communication is related to the client's preference for a trusting relationship (see Hypothesis 5).

Additional results show that Flexibility and Trust are related to more relationship commitment (see Hypothesis H3 and H4). In addition, long-term commitment and trust both lead to more cooperation (see Hypotheses H7 and H8). Therefore, client cooperation is the ultimate outcome of a successful relationship; a relationship where there is flexibility, restrained power, information, expectations beyond the audit, commitment, and trust. 
The client's willingness to remain at Arm's Length is related to Trust (see Hypothesis 9) but is not related to relationship Commitment (see Hypothesis 10). To the best of our knowledge, this is the first study that shows that the buyer-seller relationship can be conducted at arm's length and is still relational (trust is an important relational approach variable, Morgan and Hunt, 1994; Sheth and Parvatiyar, 2000).

From these results, we find that commitment is a necessary antecedent for cooperation (as others have found, Morgan and Hunt, 1994; Ruyter and Wetzels, 1999), but commitment is not enough to encourage the client to willingly remain at arm's length. Trust is the key mediating variable that influences both the client's willingness to cooperate and remain at arm's length.

Finally, our results show that commitment is a central construct, which is consistent with other client-auditor relationships (Ruyter and Wetzels, 1999) and in the relationship marketing literature (Dwer et al 1987; Morgan and Hunt 1994 (Figure 1). However, commitment (with the absence of trust) is not enough to assure a successful auditorclient relationship (both cooperative and at arm's length).

This study has practical implications for marketing managers of audit firms. It is important that service providers look beyond the service that is paid for by the client, which could be referred to as a value-added service. This added-value service, enhanced by increased communication and flexibility goes beyond the prescribed service and is not billable. This added-value service, as demonstrated by our model (see Figure 1), should result in client cooperation. Client cooperation could result in better business for the supplier. For example, if clients are more cooperative they could be willing to accept price increases and be less willing to leave the supplier in the case of less than satisfactory service quality. Therefore, the suppliers of audit services should invest in their clients and provide valuable information such as information sessions, training and webinars to keep clients up to date on industry data. The suppliers of financial services should also communicate frequently with clients to assure the clients are aware of the specific norms of the supplier, which, if shared, have been shown to increase trust (see Figure 1). The auditor's ability to increase client's trust will be important in order to help the auditor conduct their audit at arm's length.

\section{Limitations}

Our study has certain limitations. Our model that represents the relationships of the study's variables shows directions that are mostly based on theoretical models. We attempted to justify the relationships with correlation analysis; however, correlation analysis only tells us if there is a relationship and not which variable is the cause and which variable is the effect.

We acknowledged the support of our hypotheses based on the correlations that were shown to be statistically significant. The correlation coefficients, however, do not show strong relationships and were significant based on the size of our sample.

We limited the number of our variables based on past theoretical models; however, other variables could have been studied which could influence a client's willingness to cooperate with their auditor.

\section{Future Research}

In this study, we asked clients about their relationship preferences. It would be interesting to extend the study to match the auditor's preferences to see if there are similarities or differences.

Our method of inquiry was a mail survey and it would be interesting to conduct a qualitative face-to-face study to determine what the important relationship variables are for clients and auditors. This study relied primarily on Relationship Marketing variables. Given that the client-auditor relationship is different from other types of 
Relationship Marketing relationships, a qualitative inquiry might determine different variables than are presented in the Relationship Marketing literature

\section{Notes}

Financial auditors: Throughout the text we will use the term auditor to signify financial auditor.

Variable inter-correlations: Some constructs were measured using 2 variables and others were measured using 1 variable. This is why in some boxes there are 2 correlation results and others have 1 correlation result.

The Solpref3 variable is a reverse item; therefore a negative correlation actually represents a positive relationship.

The Solpref3 variable is a reverse item; therefore a positive correlation actually represents a negative relationship.

\section{References}

1. Arens, A., R. Elder et al. 2007. Auditing and Other Assurance Services. Prentice-Hall.

2. Axelrod, R. 1984. The Evolution of Cooperation. Basic Books.

3. Axelrod, R. 1997. The Complexity of Cooperation. Princeton University Press.

4. Beattie, V., S. Fearnley et al. 2000. "Behind the Audit Report: A Descriptive Study of Discussions and Negotiation Between Auditors and Directors ". International Journal of Auditing, 4: 177-202.

5. Beattie, V., S. Fearnley et al. 2001. Behind Closed Doors. Palgrave.

6. Beattie, V., S. Fearnley et al. 2004. «A Grounded Theory Model of Auditor-Client Negotiations ». International Journal of Auditing, 8: 1-19.
7. Brandenburger, A. and B. Nalebuff (1996). Co-opetition. New York, Doubleday

8. CICA. 2012. Assurance Handbook. The Canadian Institute of Chartered Accountants.

9. Eilifsen, A., W. R. Knechel et al. 2001. «Application of the Business Risk Audit Model: A Field Study ». Accounting Horizons, 15(3): 193-207.

10. Ferguson, R., M. Paulin et al. 2005. «Relational governance communication and the performance of biotechnology partnerships». Jounal of Small Business and Entreprise Development, 12(3): 395-408.

11. Fink, R., L. Edelman et al. 2007. "Supplier performance improvements in relational exchanges. » Journal of Business and Indistrial Marketing 22(1): 29-40.

12. Flint, D. (1988), Philosophy and Principles of Auditing, London Macmillan Education LtD

13. Fontaine, Richard and Claude Pilote (2011), "An empirical study of Canadian companies to determine clients' preferred relationship with their financial auditor" Journal of Marketing Trends - Volume 1 (September).

14. Ganesan (1994) Determinants of LongTerm Orientation in Buyer-Seller Relationships Journal of Marketing, Vol.58

15. Goldman, A. and B. Barlev. 1974. "The Auditor-Firm Conflict of Interests: Its Implications for Independence ». The Accounting Review, 49(4): 707-718.

16. Gronroos, C. 1991. "The Marketing Strategy Continuum: Towards a Marketing Concept for the 1990s». Management Decision, 29(1): 7-13.

17. Gronroos, C. 1994. «From Marketing Mix to Relationship Marketing: Towards a

Richard Fontaine and Luciano Pilotti (2016), Journal of Accounting and Auditing: Research \& Practice, DOI: 10.5171/2016.207562 
Paradigm Shift in Marketing ». Management Decision, 32(2): pg 4.

18. Gronroos, C. 1997. «Value-driven Relational Marketing: from Products to Resources and Competencies ». Jounal of Marketing Management, (13): 407-419.

19. Gronroos, C. 2000. Service Management and Marketing. John Wiley \& Sons.

20. Gujarati (2003), Basic Econometrics, fourth edition, McGraw Hill

21. Heide, J. and G. John. 1992. "Do Norms Matter in Marketing Relationships ? » Journal of Marketing, 56(2): 32.

22. Herda, D. N., \& Lavelle, J. J. (2012). How the auditor-client relationship affects the extent of value-added service provided to the client. Current Issues in Auditing, 7(1), P9P14.

23. IESBA, 2013 International Ethics Standard Board of Accountants. 2013 Handbook of the Code of Ethics for Professional Accountants. Retrieved from http://www.ifac.org/publicationsresources/2013-handbook-code-ethicsprofessional-accountants

24. IFAC (2006). "International Ethics Standards Board for Accountants " Code of Ethics for Professional Accountants

25. Kaufmann, P. and R. Dant 1992. «The Dimensions of Commercial Exchange ». Marketing Letters, 3(2): 171-185.

26. Lui, S. S., \& Ngo, H. Y. (2012). Drivers and Outcomes of Long-term Orientation in Cooperative Relationships. British Journal of Management, 23(1), 80-95.

27. Macneil, I. 1980. The New Social Contract Binghamton, Yale College.

28. Morgan, R. and S.Hunt (1994), "The Commitment-Trust Theory of Relationship
Marketing" The Journal of Marketing Vol 58 No 3

29. Paulin, M., J. Perrien et al. 1997. «Relational contract norms and the effectiveness of commercial banking relationships ». International Journal of Service Industry Management, 8(5): pg 435.

30. Paulin, M., R. Ferguson et al. 2000. «Effectiveness of Relational and Transactional cultures in commercial banking: putting client-value into the competing values model ». The International Journal of Bank Marketing, 18(7): 328.

31. Pels, J., N. Coviello et al. 2000. «Integrating Transactional and Relational Marketing Exchange: A Pluralistic Perspective ». Jounal of Marketing Theory and Practice, 8(3): pgs 11-20.

32. Ravald, A. and C. Gronroos 1996. "The value concept and relationship marketing». European Journal of Marketing, 30(2): 19-30.

33. Rennie, M. D., L. S. Kopp, et al. 2010. "Exploring Trust and the Auditor-Client Relationship ». Working Auditing: A Journal of Practice \& Theory Vol. 29, No. 1

34. Rokkan and Haugland (2002), Developing relational exchange, European Journal of Marketing, Vol.36 No. $1 / 2$

35. Rokkan, Heide, Wathne (2003), Specific Investments in Marketing Relationships: Expropriation and Bonding Effects, Journal of Marketing Research, Vol. 40, No. 2

36. Ruyter and Wetzels (1999), Commitment in auditor-client relationships: antecedents and consequences, Accounting, Organizations and Society, 24.

37. Sheth, J. and A. Parvatiyar. 2000. Relationship Marketing, Sage Publications.

38. Tse, A., Trotman, K., \& Cheng, M. (2012). The impact of the existence and timing of

Richard Fontaine and Luciano Pilotti (2016), Journal of Accounting and Auditing: Research \& Practice, DOI: 10.5171/2016.207562 
concessions in multi-period auditor-client negotiations. wwwdocs.fce.unsw.edu.au

39. Viio, P., \& Grönroos, C. (2015). How buyer-seller relationship orientation affects adaptation of sales processes to the buying process. Industrial Marketing Management.

40. Williamson, 0. 1975. Markets and Hierarchies: Analysis and Antitrust Implications. New York : The Free Press. 